\title{
Study on the Application of Traditional Cultural Symbols in Visual Communication Design
}

\author{
Li Yixuan \\ Weinan Normal University, Silk Road Institute of the Arts, Weinan, Shaanxi, 714000
}

Keywords: Traditional culture symbol; Visual communication design; Application value; Development suggestion

\begin{abstract}
Traditional culture is the wealth of the nationalities. The traditional culture of China has a long history and ethnic characteristics. As an important part of traditional culture, the traditional cultural symbols affect the thinking and behavior of each generation. Therefore, the application of traditional cultural symbols in the design of visual communication can reflect the relationship between the traditional and the modern. And it has a high reference value for visual communication design. This paper analyzes the application of traditional cultural symbols in visual communication design. It analyzes the existing problems and puts forward corresponding suggestions for development. It provides reference for visual communication designers and enhances their own value.
\end{abstract}

\section{Introduction}

Traditional cultural symbols are an indispensable part of Chinese traditional culture system. Therefore, the research focus of traditional cultural symbols in visual communication design is the exploration of traditional cultural symbols in visual communication design. However, the traditional culture of China has a long history and rich heritage. Even in the information age, traditional cultural symbols have far-reaching significance [1]. At present, the design of visual communication works more commercialized. The cultural background and aesthetic thoughts inherent in traditional cultural symbols still affect people's behavior and play an important role [2]. In order to comply with the development of the times, the symbols of traditional Chinese culture should be compatible with the times. Based on the local culture, combined with the contemporary advanced technology and the rich traditional cultural symbols, it can enhance the traditional cultural symbols in the visual communication design [3].

\section{Overview of traditional cultural symbols}

In a broad sense, cultural symbols are symbols that reflect the traditional cultural features of the region. They can represent the geographical features of different ethnic groups. China's traditional cultural symbols refer to those traditional cultural symbols. They reflect the Chinese national characteristics. These symbols contain the national ideology with Chinese characteristics. Therefore, in the study of traditional cultural symbols, we should first consider the cultural heritage of traditional cultural symbols and study them as communicative. Human beings themselves have symbolic thinking. And they are guided by their own thinking. Therefore, the process of mankind's creation of spiritual culture can be also regarded as a process of creating cultural symbols. There are 5,000 years of Chinese history. In the process, mankind has created many unique traditional cultural symbols. In the process of creating cultural symbols human beings is an interpretation of their own nature. So the symbol of living space is the real living space. Visual communication design is the cultural carrier of traditional cultural symbols.

The basic characteristics of traditional cultural symbols include symbol type, symbolic structure, symbolic attributes and value orientation. Analysis of the main features of Chinese traditional cultural symbols can reveal its basic mental outlook. The ideological character of Chinese traditional cultural symbols mainly lies in ethics. The political system is the center and it serves the 
political system. At the same time, it promotes the traditional culture.

\section{Application of traditional cultural symbols classification}

The traditional cultural symbolic classification of our country is divided into two major systems. One is the natural system formed by man and the world, and the other is the man-made artificial system based on the natural system. Natural system refers to the natural phenomenon. Artificial system is used to the natural scene and the transform itself.

\subsection{Natural symbols}

The natural symbol is an important part of the traditional cultural symbol. It comes from nature and covers many cultural resources in nature. For example, there are animals and birds, birds and insects, mountains and rivers, trees and forests. On the basis of their own laws of growth and development of the track for observation, designers can understand the design resources. It enriches the design inspiration. Therefore, art comes from nature and nature is the foundation of all design activities. Outstanding designers can use information to elicit human resonance and produce the same natural feel. Human beings always have a sense of dependence on nature. This mainly due to that humans were originally evolved from animals. So in the design of traditional elements, it makes full use of natural things. In an innovative and traditional form of display, visual communication give full play to the advantages of natural symbols in the design.

\subsection{Artificial symbols}

Our country has a long history, single feudal dynasties have lasted for thousands of years, there are many problems. However, these also played a positive role at the time, such as maintaining social stability, promoting social development and enriching cultural resources, leaving huge wealth for future generations. As we all know, the feudal dynasty level clear, dragon-shaped pattern can easily distinguish between people and the imperial elite, consolidate the status and politics of the rulers. In addition, the ancient landscape culture is also very popular, the ancients love landscape, so these man-made symbols can reflect the history of the dynasty and then people's thinking and behavior. Therefore, introducing the symbol of the times in visual communication design can enhance the cultural connotation of design. Man-made symbols are generally divided into two categories, such as physical symbols such as clothing, calligraphy and painting, and porcelain, as well as gas symbols such as Taiji gossip and auspicious decoration. Speaking of calligraphy and porcelain, people around the world first of all think of China, the gas symbol will be more used in furniture, accessories, and different nationalities and regions have different representatives. For example, the auspicious cloud torch pattern for the Olympic Games draws on China's traditional cultural symbols and makes improvements on the basis of this to incorporate the flavor of the times.

\section{Traditional cultural symbols in the visual communication design}

\subsection{The traditional cultural symbols in the visual communication of goods in the application}

The symbol of traditional culture in our country has a long history and rich resources, to a certain extent, promoted the development of visual communication design. Today, in the information age, the visual communication design of goods needs a higher level of development. Therefore, it is necessary to draw lessons from traditional culture and carry out research and analysis to obtain design inspiration. This is the future development trend of design aesthetics. With the rapid social and economic development, people's living standards have made great strides. However, aesthetic requirements have also come up. All sectors of society pay more attention to the development of traditional cultural symbols. Therefore, the design of visual communication of goods should not only follow the development of the times but also meet the new needs of all walks of life in combination with traditional culture. For example, China's four major banks Logo design are visual communication design in the application of the traditional case of a typical case of culture. 


\subsection{The application of traditional cultural symbols in all fields of society}

Traditional Chinese culture is widely used. Traditional arts such as calligraphy and traditional opera have an important influence on people's living habits. Calligraphy is the representative of traditional culture. The works are rich in oriental style, smooth lines and graceful shape, which are unmatched by other writing works. Nowadays, people are accustomed to typing rather than handwriting because of the reason of computer. However, people are more and more longing for traditional calligraphy. All these reflect the status and function of traditional culture from the side. In 1949, Shanghai Art Film Studio integrated the ink painting into the animation and created it with the simplest points, lines and surfaces. They give full play to the advantages of Chinese traditional ink and wash elements and embodying the artistic effect of oriental uniqueness. Fuwa image of the Olympic Games is derived from folk culture, such as Fuwa Nini. It is the anthropomorphic kite, the perfect combination of traditional culture and modern culture. And it promotes the rapid development of folk culture.

\subsection{Traditional cultural symbols in the apparel design}

With the development of the times, people's application of traditional culture is also more in-depth. For example, Fan Bingbing dressed in robes and red carpet. It successfully aroused the concern of all sectors of society and it became the headlines at the time coverage. Today, more and more traditional cultural symbols are used in clothing, such as clothing patterns and colors, clothing accessories and accessories, all with rich Chinese characteristics. There are also public service announcements such as Chinese dream advertising, little girls dressed in traditional costumes, and values conveying Chinese dreams. All these are the successful examples of the integration of traditional culture and modern culture. Second, many garment designers refer to the paper-cut culture, making the artistic image more vivid and interesting.

\section{To improve the traditional cultural symbols in the visual communication design value}

\subsection{Add traditional cultural symbols to college courses}

According to the survey and study, colleges and universities did not set relevant courses and ignored the teaching of Chinese traditional culture symbols. This is also the commonness of the present society. There are even some art and design professionals. They do not attach importance to traditional cultural symbols and they will not conduct in-depth research. Therefore, colleges and universities in the design of visual communication design courses introduce the traditional symbols. It develops a sound teaching plan and carries out the traditional cultural symbol teaching. Which ensure the traditional Chinese cultural symbols. As a result, its continuous innovation maintains the vitality of traditional Chinese cultural symbols.

\subsection{Establishment of Chinese traditional cultural symbol organization}

In May 2016, the Ministry of Civil Affairs issued a list of relevant associations, including traditional cultural associations. After the abolition of interest associations by the Ministry of Civil Affairs of the People's Republic of China, they also support traditional successors of culture and provide strong guarantees for the sustainable development of civil society. For example, Sichuan Association for the Protection and Propagation of Traditional Culture is a national call for the establishment of traditional Chinese cultural heritages. It has also perfected the Association for the Protection of Chinese Culture and carried out related activities to promote exchange and interaction among researchers and maximize the transmission of traditional cultural symbols.

\subsection{To carry out a wealth of design activities, mining the spirit of traditional cultural symbols}

At present, China's visual communication design has also begun to integrate into the traditional cultural symbols. But it has been a lack of new ideas, imitation, plagiarism occurs frequently. This requires the state to formulate relevant documents and organize traditional cultural symbolic design activities to mobilize the community's craze for learning traditional culture and to inherit and 
innovate traditional cultural symbols. Visual Communication Design for the traditional cultural symbols of the general reference is divided into two aspects, namely, patterns and colors. However, the core of the traditional culture symbol is the spiritual connotation of the nation. Therefore, designers should dig deep into the deep connotation of the traditional culture symbol. It does not stop at the superficial pattern and color and it incorporates visual communication design into people's aesthetic concept.

\section{Chinese traditional cultural symbols in the visual communication design value}

\subsection{Visual Communication Design Traditional Cultural Value Innovation}

Any visual form is based on the spatial modeling factors, while the visual elements of the manifestation of traditional cultural symbols are based on the formal characteristics of the artistic symbols. Art creation is a deep excavation of the cultural symbols. The cultural symbols are employed to understand the current social and cultural heritage and visual effects. However, they are not used to be copy. On the basis of the original intention of the culture of a kind of innovation and transformation, they are employed to be transformed. Therefore, visual communication design is to contact the current living environment and natural image. Reconstruction of creativity is a kind of innovation, which is based on the preservation of the traditional cultural symbols and based on a process of its creation, rather than a simple form of innovation.

\subsection{Visual Communication Design in the reproduction of traditional cultural values}

In the field of visual communication design, the traditional cultural symbols have always been the focus of attention. And the two are mutually reinforcing and complement each other. Studying the traditional cultural symbols in depth can help us to understand the essence of the traditional cultural symbols and comprehensively and systematically understand the living space of national cultural symbols. The effective inheritance of Chinese traditional cultural symbols provides favorable conditions for the innovation and development of cultural symbols, which are reflected in many aspects of life, such as national costumes, handicrafts and so on. Only by keeping the cultural ecology can we arouse the newborn of the cultural symbols. The cultural forms of cultural symbols in visual communication design are produced in human life and influenced by many aspects such as folk culture, social background and life style. Such as paper cutting, shadow puppets, carving, masks, etc., all contain the local folk cultural symbols of belief and entertainment and other spiritual areas. Therefore, when analyzing the traditional cultural symbols, we should not only understand it from the concept of painting, but also integrate the material culture and spiritual culture and emphasize the artistic value of cultural symbols to grasp the value of visual communication design.

\section{Conclusions}

Nowadays, the art and culture are more diversified, making reasonable use of our traditional cultural symbols in the visual communication design and promoting the inheritance of the national spirit. As a result, they effectively convey the national cultural heritage and create design works that are in line with the characteristics of the times. Visual communication designers need to refine the highlights of traditional cultural symbols and transform them with new high-tech means such as computers. By introducing auspicious patterns into modern visual communication design, they can create design works that are in keeping with the times.

\section{References}

[1] Wu Wenyong. The Application of Chinese Traditional Elements in Visual Communication Design [J]. Grand Theater, 2014 (12): 52

[2] Zhang Yuqin. Chinese traditional visual elements in the design of animation costumes [D]. Jiangnan University, 2013 (06): 55

[3] Chen Hui. Analysis of the Symbol of National Culture in Visual Communication Design [J]. Journal of Nanjing Arts Institute, 2016 (6): 169-172 